\title{
Initial study on the use of support vector machine (SVM) in tool condition monitoring in chipboard drilling
}

\author{
Albina Jegorowa ${ }^{1}$ [ $\cdot$ Jarosław Górski ${ }^{1}$ Jarosław Kurek ${ }^{2} \cdot$ Michał Kruk $^{2}$
}

Received: 14 January 2019 / Published online: 21 June 2019

(c) The Author(s) 2019

\begin{abstract}
The paper presents the idea of using support vector machine algorithm in a tool wear identification system in chipboard drilling. The indirect sources of information about tool wear were: feed force, cutting torque, acceleration of jig vibration, audible noise, and ultrasonic acoustic emission signals. The drills were classified (analogous to traffic rules) as "Green" (able to work), "Yellow" (warning state) or "Red" (unable to work-replacement needed).
\end{abstract}

\section{Introduction}

One of the main obstacles to the further development of automation in woodmachining is the inability to create autonomous tool condition monitoring (TCM) systems. This is true in spite of the fact that advanced research works on this issue have been going on for about 20 years (e.g., Lemaster et al. 2000; Szwajka and Górski 2006; Wilkowski and Górski 2011; Górski et al. 2019). Nowadays, we are standing at the threshold of the fourth industrial revolution (Industrie 4.0) and we simply need i.a. "autonomous devices, sensors and machines that monitor themselves" (Bergweiler 2016). This paper presents an idea of using support vector machine (SVM) algorithm in TCM system in chipboard drilling. The SVM is one of the most efficient classification algorithms (Scholkopf and Smola 2002). It is a feedforward network of one hidden layer (the kernel function layer) known for its good generalization ability. The learning problem of SVM is formulated as the task of separating the learning vectors into two classes of the destination values either $\mathrm{di}=1$ (one class) or $\mathrm{di}=-1$ (the opposite class), with the maximal separation margin. This margin is formed in the learning stage using the assumed value of

Albina Jegorowa

albina_jegorowa@sggw.pl

1 Faculty of Wood Technology, Warsaw University of Life Sciences, 166 Nowoursynowska St, 02-787 Warsaw, Poland

2 Faculty of Applied Informatics and Mathematics, Warsaw University of Life Sciences, 166 Nowoursynowska St, 02-787 Warsaw, Poland the regularization constant $\mathrm{C}$ providing some immunity of classifier to the noise.

\section{Materials and methods}

A standard $\mathrm{CNC}$ router, six tungsten carbide drill bits (five experimental and one control) and melamine faced chipboard were used. Every experimental drill was exposed to seven or eight work cycles (during which a predetermined number of holes were drilled). This has gradually changed the drills' state from brand new to absolutely worn. The extent of the wear of the external corner [W (mm)] was adopted as a drill condition indicator and periodically (between work cycles) monitored using a microscope (Mitutoyo TM-500). Based on this, the drill immediately got classified (analogous to traffic rules) as "Green" (for $\mathrm{W}<0.2 \mathrm{~mm})$, "Yellow" $(0.2 \mathrm{~mm}<\mathrm{W}<0.35 \mathrm{~mm})$ or "Red" (W>0.35 mm). "Green" means "able to continue working", "Yellow" is "warning state" and "Red" means "unable to work-replacement needed". After such identification, the drill was sent to the research stand, which was set up to measure the following: feed force, cutting torque, acceleration of jig vibration, audible noise and ultrasonic acoustic emission (Fig. 1). There it was used to make a series of 5 holes, recording the aforementioned signals. Then, a series of 3 holes was made using the control drill (which was "Green" all the time).

After the experimental research was completed, the standard machine learning algorithm was performed using MATLAB environment. The SVM of the Gaussian kernel was used in the present solution. The hyperparameters $\sigma$ 


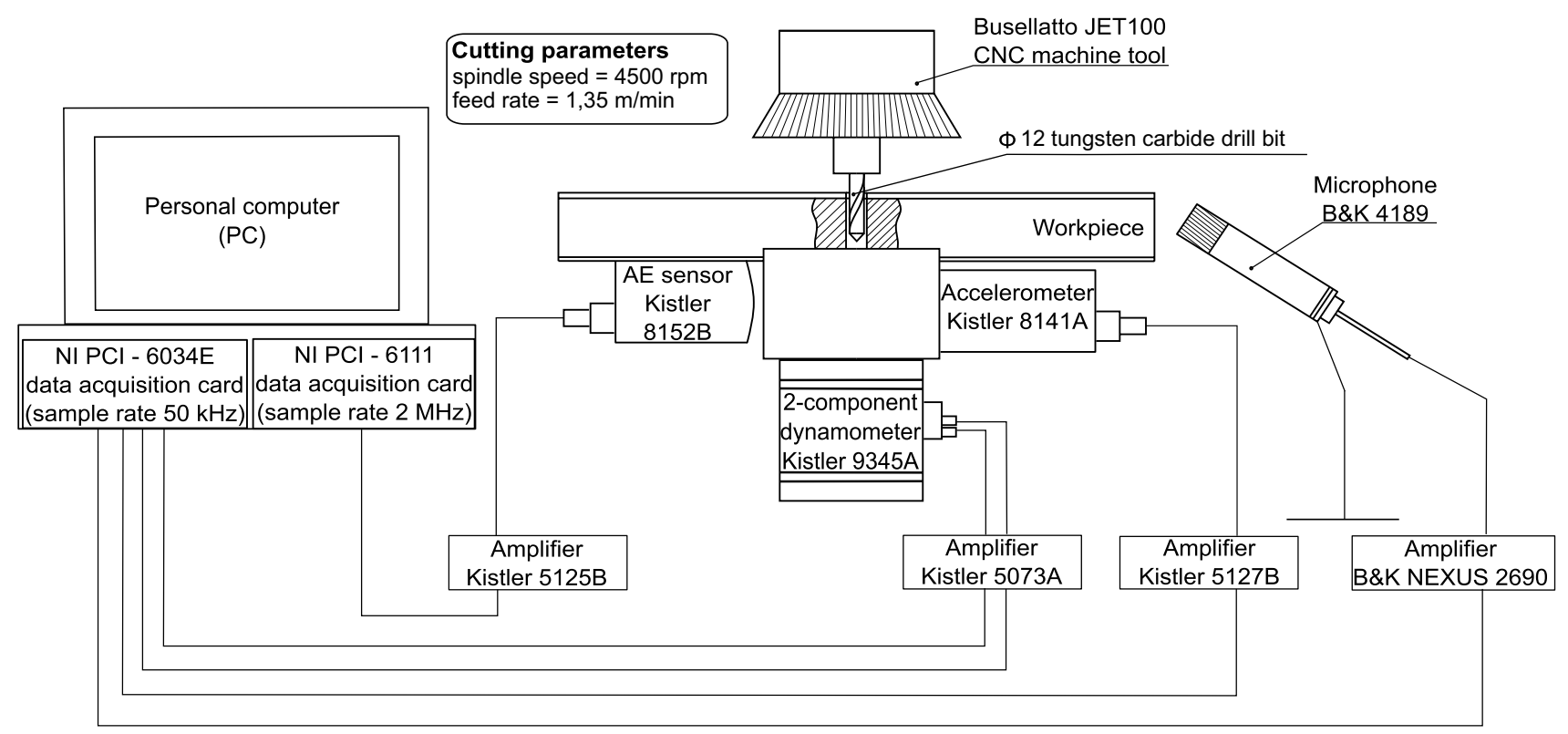

Fig. 1 Scheme of research stand and cutting parameters used in the experiment

of the Gaussian function and the regularization constant $\mathrm{C}$ were adjusted by repeating the learning experiments for the set of their predefined values and choosing the best one at the "training data" sets. The optimal values of these parameters were $\gamma=0,001$ and $C=75$. The "training data" was the database concerning five drills (there were always four experimental drills and the control drill), which covered both knowledge of their real current condition ("Green", "Yellow" or "Red"), as well as features of all signals recorded with their participation on the measuring stand. All features used in the study were extracted by means of standard functions available in MATLAB (total number of features was 455). The "test data" included features of all signals recorded with 1 experimental drill, which had not been used to create the "training data" set. Then, the SVM algorithm was activated in order to identify the current condition of the test drill based only on the features of signals included in the "test data" set. The five different options of the "test data" (including, one by one, each of the five experimental drills) were set up. Thus, the five separate tests were performed, but only one total confusion matrix was determined.

\section{Results and discussion}

The effectiveness of the SVM algorithm can be analyzed based on the confusion matrix (Table 1). In this table the rows represent the tool conditions resulting from (not always perfect) the choice of the SVM classifier, and columns reflect the real tool conditions (established by the microscopic observations). In the cells located on the diagonal (from the
Table 1 Confusion matrix (total number of identification cases: 215)

\begin{tabular}{lllll}
\hline Output tool condition & "Green" & $30.2 \%$ & $4.7 \%$ & $0 \%$ \\
& "Yellow" & $4.7 \%$ & $14.0 \%$ & $0 \%$ \\
& "Red" & $0 \%$ & $9.3 \%$ & $37.2 \%$ \\
& & "Green" & "Yellow" & "Red" \\
& \multicolumn{3}{c}{ Target tool condition } \\
\hline
\end{tabular}

upper left to the lower right corner), there are percentages that show the frequency of perfect recognition of the drill condition. It means that the overall accuracy of classification was $81.4 \%(30.2 \%+14.0 \%+37.2)$. Moreover, there was no fatal confusion between "Green" and "Red" drills (in the upper right and lower left corner, $0 \%$ can be seen).

\section{Conclusion}

The overall accuracy of tool wear identification based on SVM algorithm was satisfactory, especially that the real "Red" drill was never recognized as the "Green" drill and vice versa (this kind of confusion would be unacceptable from a practical point of view). Moreover, the real "Red" drill was never considered to be the "Yellow" drill.

\section{Compliance with ethical standards}

Conflict of interest On behalf of all authors, the corresponding author states that there is no conflict of interest. 
Open Access This article is distributed under the terms of the Creative Commons Attribution 4.0 International License (http://creativeco mmons.org/licenses/by/4.0/), which permits unrestricted use, distribution, and reproduction in any medium, provided you give appropriate credit to the original author(s) and the source, provide a link to the Creative Commons license, and indicate if changes were made.

\section{References}

Bergweiler S (2016) Smart factory systems-fostering cloud-based manufacturing based on self-monitoring cyber-physical systems. Int J Adv Syst Meas 9(1,2):91-101

Górski J, Szymanowski K, Podziewski P, Śmietańska K, Czarniak P, Cyrankowski M (2019) Use of cutting force and vibro-acoustic signals in tool wear monitoring based on multiple regression technique for compreg milling. Bio Res 14(2):3379-3388
Lemaster RL, Lu L, Jackson S (2000) The use of process monitoring techniques on a CNC wood router. Part 1 Sensor selection. For Prod J 50(7/8):31-38

Scholkopf B, Smola A (2002) Learning with kernels. MIT Press, Cambridge

Szwajka K, Górski J (2006) Evaluation tool condition of milling wood on the basis of vibration signal. J Phys 48(2006):1205-1209

Wilkowski J, Górski J (2011) Vibro-acoustic signals as a source of information about tool wear during laminated chipboard milling. Wood Res 56(1):57-66

Publisher's Note Springer Nature remains neutral with regard to jurisdictional claims in published maps and institutional affiliations. 